\title{
Microcalcification-Associated Breast Cancer: Presentation, Successful First Excision, Long-Term Recurrence and Survival Rate
}

\author{
Marga B. Rominger ${ }^{a} \quad$ Carolin Steinmetz $^{b}$ Ronny Westerman ${ }^{c} \quad$ Annette Ramaswamy $^{d}$ \\ Ute-Susann Albert ${ }^{\mathrm{e}}$ \\ a Department of Radiology, University Hospital Zürich, Switzerland; \\ ${ }^{b}$ Department of Pediatric Psychiatry, University Hospital Würzburg, Germany; \\ ${ }^{c}$ Competence Center for Mortality Follow-up, German National Cohort Study, University Hospital of Philipp University Marburg, Germany; \\ ${ }^{\mathrm{d}}$ Department of Pathology, University Hospital of Philipp University Marburg, Germany; \\ e Department of Gynecology and Obstetrics, Krankenhaus Nordwest, Frankfurt/M., Germany
}

\section{Keywords}

Breast cancer · Imaging · Prognostic value - Recurrence · Survival

\section{Summary}

Introduction: In this study we evaluated mammographic, histological and immunohistochemical findings for microcalcification-associated breast cancer with regards to breast-conserving therapy, recurrence and survival rate. Patients and Methods: We retrospectively analyzed 99 consecutive, non-palpable and microcalcification-associated breast cancers ( 94 women) that were treated surgically between January 2002 and December 2003 at a national academic breast cancer center. Calcifications were classified according to the Breast Imaging Reporting and Data System (BI-RADS). Descriptors, surgical outcome and histological findings were assessed. Recurrences and survival rates were evaluated based on medical records, standardized patient questionnaires and/or contacting the physician. Results: 42 of the 99 lesions $(42.4 \%)$ were invasive carcinomas, 57 (57.6\%) were pure ductal carcinoma in situ (DCIS). 6 out of 99 (6.1\%) lesions were triple negative, and 29 (29.3\%) were HER2/neu positive. Successful first excision rate was 76/99 lesions (76.8\%). Breast conservation was achieved in $73.7 \%$ (73/99). 10 women showed local recurrences without negatively impacting survival. The recurrences included round/punctate, amorphous, fine pleomorphic, and fine linear or fine-linear branching descriptors. The breast cancer-specific long-term survival rate was 91/94 (96.8\%) for a mean follow-up of 81.4 months. The 3 patients who died due to breast carcinoma showed fine pleomorphic calcifications, and had nodal-positive invasive carcinoma at diagnosis. Conclusion: Microcalcification-associated breast cancers are frequently treated with breast-conserving therapy. Continuous clinical and mammographic follow-up is recommended for all descriptors.

(c) 2015 S. Karger GmbH, Freiburg

\section{Introduction}

Several authors have reported that the presence of mammographic calcifications is indicative of poor long-term clinical outcome [1-8]. The descriptors of calcification morphology represent a prognostic indicator for grading $[9,10]$, successful first excision $[11]$ and survival $[1,6,12,13]$. Tabar et al. $[1,12]$ and others $[6,7$, 13] have shown that the presence of fine linear or fine linear branching (casting type) calcifications is a prognostic indicator for poorer survival. Holland et al. [14] suggested that round/punctuate calcifications are an indicator for unsuccessful first excision and recurrence.

The major progress in breast cancer survival achieved during the last decade is based upon adjuvant treatment of breast cancer [15]. Breast cancer is a heterogeneous disease as regards its geneexpression profile, pathological and mammographic appearance, biological behavior and the response to treatment. Management of breast cancer in clinical practice has evolved with the availability

\section{KARGER}

Fax +497614520714

\section{() 2015 S. Karger GmbH, Freiburg}

1661-3791/15/0106-0380\$39.50/0 
and use of immunohistochemistry. However, for microcalcification-associated breast cancers little is known about the incidence, distribution and impact of immunohistochemistry.

Therefore, we performed a retrospective analysis of our database to assess the outcome of microcalcification-associated breast cancers with special focus on Breast Imaging Reporting and Data System (BI-RADS) descriptors of calcification morphology, histology, and immunohistochemistry with respect to successful first surgery, breast-conserving surgery, recurrence and long-term survival rate.

\section{Patients and Methods}

\section{Study Design}

This retrospective cohort study included the long-term follow-up of 99 consecutive malignant and non-palpable lesions that contained microcalcifications (from 94 women) that were treated with hook-wire guided surgery between January 2002 and December 2003 in an academic tertiary-care institution.

\section{Patients}

The institutional review board approved this study and waived the requirement for informed consent. Data on pathological features, surgery, recurrence, and survival outcomes were gathered from our hospital database. A semi-structured questionnaire was send by mail to all women for whom a lack of recurrence or survival was unclear at the validation date $(n=47) .32$ out of 47 women or their husbands answered the questionnaire by mail. The general practitioners of the 15 women from whom no reply to our initial questionnaire was received were contacted either by mail or phone. Information on recurrence and survival was obtained for 8 of these 15 women. 4 out of remaining 7 patients were successfully contacted by phone and information was obtained. Thus, of 94 women, 3 were lost to follow-up; for 6 women we lacked information on local/regional recurrence. The observation period was either from the time of first surgery until 1 January 2010 (defined as time point 1) or information gained later than 1 January 2010 (defined as time point 2). The last patient was followed up until 23 January 2012.

\section{Mammography Reading}

Patients and mammography readings were part of previous evaluations related to the positive predictive value for malignancy of suspicious descriptors of microcalcifications and presence of additional parenchymal findings according to the American College of Radiology (ACR) BI-RADS, 4th edition [16] and up-dated to the ACR BI-RADS 5th edition for this study [17]. Only 1 descriptor from each suspicious morphological class of microcalcifications was used to describe the findings in a mammogram. In the case of multiple different calcification forms, the more suspicious category was chosen. Suspicious calcifications were amorphous, coarse heterogeneous, fine pleomorphic, and fine linear or fine-linear branching calcifications. Round/punctate calcifications were based on selected suspicious round/punctate calcifications that underwent histological assessment.

\section{Histology}

Ductal carcinoma in situ (DCIS) and invasive carcinoma were considered to be malignant. Grading for invasive carcinoma was performed according to Elston and Ellis [18] and for DCIS according to the grading part of the Van Nuys classification [9]. If there were multiple histological findings within 1 specimen, the most suspicious histopathology was considered the final histological result.

\section{Immunohistochemistry}

In 2002 and 2003, estrogen receptors were assessed using monoclonal mouse anti-human estrogen receptor alpha clone 1D5 (Dako M 7047) at a dilu- tion of 1:100, progesterone receptors using monoclonal mouse anti-human progesterone receptor PgR 636 (Dako M 3569) at a dilution of 1:50, and human epidermal growth factor receptor 2 (Her2/neu) using polyclonal rabbit antihuman c-erB-2 oncoprotein (Dako A 0485) at a dilution of 1:500. In 2002 and 2003, the proliferation marker Ki-67 was not routinely assessed. For 5 lesions immunochemistry was either not available or not feasible due to small tumor size.

\section{Therapy}

Therapy was performed according to contemporary national guidelines. In 2002 and 2003, a resection free margin greater than $5 \mathrm{~mm}$ was standard (today greater $1 \mathrm{~mm}$ ). Successful first excision rate excludes prior diagnostic procedures. Final mastectomy rate was defined as mastectomy for the initial disease and excludes later mastectomy for recurrence. Final mastectomy rate includes patients with the wish for mastectomy despite national recommendations.

\section{Statistics}

For statistical analysis, we used Excel (Excel 2000, Microsoft, Redmond, WA), software SPSS 22 (IBM SPSS Statistics, Armonk, NY) and STATA 12 IC (Stata Corp, College Station, TX). For the relationship between descriptors with tumor characteristics and treatment, we used a $\mathrm{Chi}^{2}$ test, Fischer Exact test or Freeman Halton test. For statistical analysis of recurrence and survival outcome, the Kaplan-Meier Estimator under the consideration of Delayed-Entry was applied using STATA 12 IC. Thus, patients with a different entrance date and observation period could be observed. The association between survival/ recurrence and descriptors of microcalcifications was determined by a Cox regression. Kaplan-Meier plots were generated for freedom of recurrence and survival. A p value below 0.05 was considered significant.

\section{Results}

\section{BI-RADS Descriptors of Calcification Morphology}

Details of mammographic descriptors in regard to tumor characteristics, surgical therapy, recurrence and survival are listed in table 1.15 out 99 lesions showed fine linear or fine-linear branching calcifications with an increased risk for grade 3 DCIS (4/8; $50.0 \% ; \mathrm{p}=0.351)$ and HER2/neu receptors positivity $(7 / 15 ; 46.7 \%$; $\mathrm{p}=0.221)$, and without increased risk for positive axillary lymph nodes ( $2 / 7$ invasive carcinoma; $28.6 \% ; \mathrm{p}=1.000)$.

The rate of successful first excision was low for round/punctate microcalcifications with $5 / 8(62.5 \% ; \mathrm{p}=0.383)$ and best for fine linear or fine-linear branching calcifications with 13 out of 15 (86.7\%; $p=0.509$ ) lesions. Final mastectomy rate was significantly higher for fine pleomorphic compared to the other descriptors of calcification morphology with $17 / 48$ (35.4\% vs. $17.6 \% ; \mathrm{p}=0.045)$.

\section{Immunohistochemistry}

Of the 99 lesions, 65 (65.7\%) were HER2/neu negative and 29 (29.3\%) positive. In comparison to HER2/neu negative lesions, Her2/neu-positive lesions showed a higher rate of axillary lymph node positivity ( $62.5 \%$ vs. $21.5 \%$; $=0.034)$, and worse grading (G3) of DCIS ( $47.6 \%$ vs. $18.8 \%$; $\mathrm{p}=0.027$, as well as worse grading (G3) of the invasive component ( $25.0 \%$ vs. $0.0 \%$; $\mathrm{p}=0.028$ ). Her2/ neu-positive lesions showed a higher unsuccessful first excision rate $(34.5 \%$ vs. $18.5 \% ; \mathrm{p}=0.090)$, as well as recurrence rate $(18.5 \%$ vs. $9.1 \%$; $\mathrm{p}=0.369) .6$ of the $99(6.1 \%)$ lesions were triple negative. 
Table 1. Tumor characteristics of microcalcification-associated, non-palpable breast cancer

\begin{tabular}{|c|c|c|c|c|c|c|}
\hline & $\begin{array}{l}\text { Coarse } \\
\text { heterogeneous }\end{array}$ & $\begin{array}{l}\text { Round/ } \\
\text { punctate }\end{array}$ & Amorphous & $\begin{array}{l}\text { Fine } \\
\text { pleomorphic }\end{array}$ & $\begin{array}{l}\text { Fine linear } \\
\text { or fine-linear } \\
\text { branching }\end{array}$ & Total \\
\hline Pathology, n & 2 & 8 & 26 & 48 & 15 & 99 \\
\hline DCIS, n (\%) & $2(100)$ & $4(50.0)$ & $13(50.0)$ & $30(62.5)$ & $8(53.3)$ & $57(57.6)$ \\
\hline Grade 1 & $0(0)$ & $2(50.0)$ & $4(30.8)^{\star}$ & $9(30.0)$ & $1(12.5)$ & $16(28.1)$ \\
\hline Grade 2 & $1(50.0)$ & $1(25.0)$ & $9(69.2)^{*}$ & $10 / 30(33.3)$ & $3(37.5)$ & $24(42.1)$ \\
\hline Grade 3 & $1(50.0)$ & $1(25.0)$ & $0(0)^{*}$ & $11(36.7)$ & $4(50.0)$ & $17(29.8)$ \\
\hline IC, n, (\%) & $0(0)$ & $4(50.0)$ & $13(50.0)$ & $18(37.5)$ & 7 (46.7) & $42(42.4)$ \\
\hline $\mathrm{T} 1$ & $0(0)$ & $3(75.0)$ & $10(76.9)$ & $13(72.2)$ & $5(71.4)$ & $31(73.8)$ \\
\hline Т 2 & $0(0)$ & $1(25.0)$ & $3(23.1)$ & $4(22.2)$ & $2(28.6)$ & $10(23.8)$ \\
\hline Т 3 & $0(0)$ & $0(0)$ & $0(0)$ & $1(5.6)$ & $0(0)$ & $1(2.4)$ \\
\hline Grade 1 & $0(0)$ & $2(50.0)$ & $2(15.4)$ & $2(11.1)$ & $1(14.3)$ & $7(16.7)$ \\
\hline Grade 2 & $0(0)$ & $2(50.0)$ & $11(84.6)$ & $14(77.8)$ & $6(85.7)$ & $33(78.6)$ \\
\hline Grade 3 & $0(0)$ & $0(0)$ & $0(0)$ & $2(11.1)$ & $0(0)$ & $2(4.8)$ \\
\hline $\mathrm{Nodal}^{+}$ & $0(0)$ & $0(0)$ & $3(23.1)$ & $7(38.9)$ & $2(28.6)$ & $12(28.6)$ \\
\hline \multicolumn{7}{|l|}{ IHC, n (\%) } \\
\hline $\mathrm{ER}^{+}$ & $1(50.0)$ & $6(75.0)$ & $19(73.1)$ & $35(72.9)$ & $13(86.7)$ & $74(74.7)$ \\
\hline $\mathrm{PR}^{+}$ & $0(0)$ & $6(75.0)$ & $21(80.8)^{*}$ & $25(52.1)^{*}$ & $11(73.3)$ & $63(63.6)^{*}$ \\
\hline HER2/neu ${ }^{+}$ & $1(50.0)$ & $1(12.5)$ & $5(19.2)$ & $15(31.3)$ & $7(46.7)$ & $29(29.3)$ \\
\hline Triple $^{-}$ & $0(0)$ & $1(12.5)$ & $2(7.7)$ & $3(6.3)$ & $0(0)$ & $6(6.1)$ \\
\hline \multicolumn{7}{|l|}{ Surgery, n (\%) } \\
\hline BCT & $2(100)$ & $6(75.0)$ & $22(84.6)$ & $31(64.6)^{*}$ & $12(80.0)$ & $73(73.7)$ \\
\hline 1st SER & $1(50.0)$ & $5(62.5)$ & $20(76.9)$ & $37(77.1)$ & $13(86.7)$ & $76(76.8)$ \\
\hline Final mastect. & $0(0)$ & $2(25.0)$ & $4(15.4)$ & $17(35.4)^{\star}$ & $3(20.0)$ & $26(26.3)$ \\
\hline Outcome, n & 2 & 8 & 23 & 46 & 15 & 94 \\
\hline RR, n (\%) & $0(0)$ & $2(25.0)$ & $2(8.7)$ & $3(6.5)$ & $3(20.0)$ & $10(10.6)$ \\
\hline MR, n (\%) & $0(0)$ & $0(0)$ & $0(0)$ & $3(6.5)$ & $0(0)$ & $3(3.2)$ \\
\hline
\end{tabular}

${ }^{\star}$ Considered significant $\mathrm{p}<0.05$.

DCIS = ductal carcinoma in situ, IC = invasive carcinoma, IHC = immunohistochemisty, ER = estrogen receptor, PR = progesterone receptor, ${ }^{+}=$positive,${ }^{-}=$negative, $\mathrm{BCT}=$ breast-conserving therapy, 1 st $\mathrm{SER}=$ successful first excision rate, mastect. $=$ mastectomy, $\mathrm{RR}=$ recurrence rate, $\mathrm{MR}=$ mortality rate.

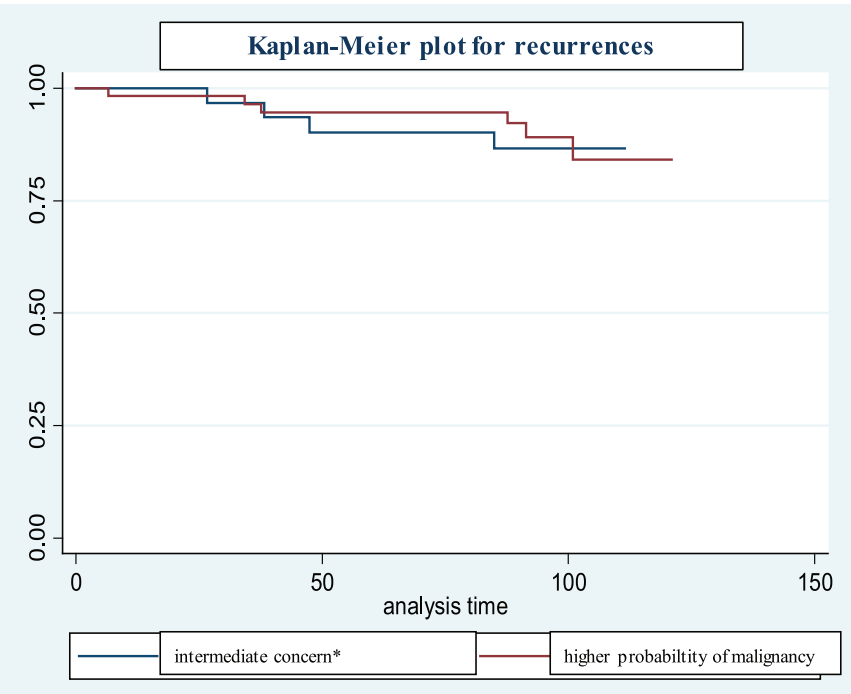

Fig. 1. Kaplan-Meier plot for recurrences.

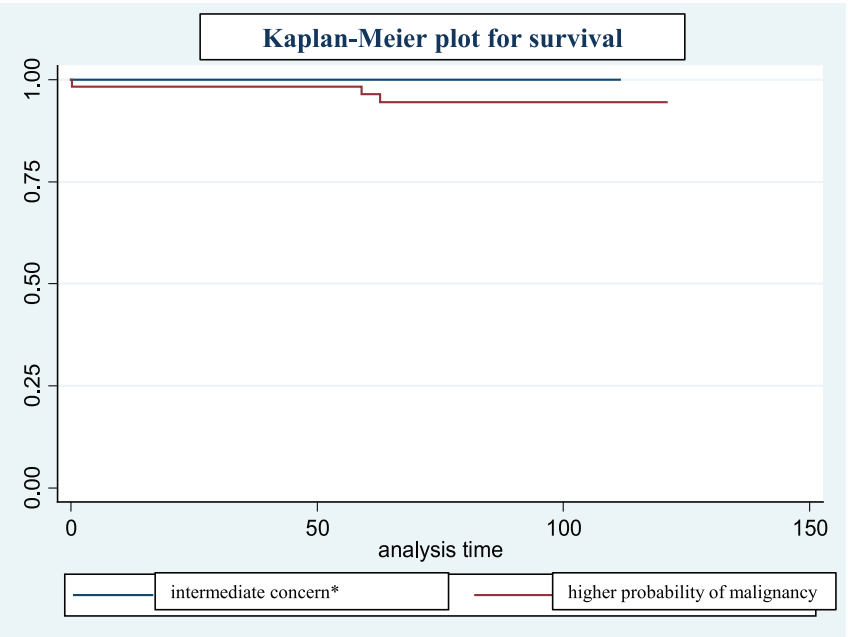

Fig. 2. Kaplan-Meier plot for survival. 
Table 2. Characteristics of women with recurrences

\begin{tabular}{|c|c|}
\hline \multicolumn{2}{|l|}{ pT stage $(n=10)$} \\
\hline pT0/Tis & 5 \\
\hline pT1 & 4 \\
\hline pT2 & 1 \\
\hline \multicolumn{2}{|l|}{ pN stage $(\mathrm{n}=5)$} \\
\hline Positive & 2 \\
\hline Negative & 3 \\
\hline \multicolumn{2}{|l|}{ Histology $(n=10)$} \\
\hline DCIS & 5 \\
\hline IC & 1 \\
\hline IC with DCIS & 4 \\
\hline \multicolumn{2}{|l|}{ Grade of DCIS $(n=5)$} \\
\hline G3 & 5 \\
\hline \multicolumn{2}{|l|}{ Grade of IC $(n=5)$} \\
\hline G1 & 1 \\
\hline G2 & 3 \\
\hline G3 & 1 \\
\hline \multicolumn{2}{|l|}{ Successful excision $(\mathrm{n}=10)$} \\
\hline Successful first excision & 6 \\
\hline 1 reexcision & 4 \\
\hline \multicolumn{2}{|l|}{ Type of surgery $(n=10)$} \\
\hline Breast-conserving therapy & 8 \\
\hline Mastectomy & 2 \\
\hline \multicolumn{2}{|l|}{ IHC status $(\mathrm{n}=10)$} \\
\hline $\mathrm{ER}^{+}$ & 7 \\
\hline $\mathrm{PR}^{+}$ & 6 \\
\hline Her $2 /$ neu $^{+}$ & 5 \\
\hline Triple $^{-}$ & 1 \\
\hline \multicolumn{2}{|l|}{$\begin{array}{l}\text { Descriptors of calcification morphology } \\
\qquad(\mathrm{n}=10)\end{array}$} \\
\hline Coarse heterogeneous & 0 \\
\hline Round/punctate & 2 \\
\hline Amorphous & 2 \\
\hline Fine pleomorphic & 3 \\
\hline Fine linear or fine linear branching & 3 \\
\hline
\end{tabular}

\section{Successful First Excision and Final Mastectomy Rate}

The numbers of successful first excision and women requiring further surgery are listed in table 1 . The successful first excision rate was $76.8 \%$ (76/99), breast-conserving rate $73.7 \%$ (73/99), and final mastectomy rate $26.3 \%$ (26/99). Successful first excision rate of grade 3 DCIS $(64.7 \%$; 11/17) was lower compared to grade 1 and 2 DCIS $(80 \% ; 32 / 40)(\mathrm{p}=0.143)$.

\section{Recurrences}

Details of women with recurrences are listed in table 2 and shown in the Kaplan-Meier plot of figure 1. A recurrence was found in 10 of the 94 women (10.6\%). The median time to recurrence was 55.5 months with a range of 6-100 months. The recurrences in 5 of the 10 women (50\%) were initially staged as pure DCIS, and 5 as invasive carcinoma. All 5 DCIS were grade 3 . The recurrences concerned all descriptors of calcification morphology except for coarse heterogeneous (0/2).

\section{Long-Term Survival}

Details of the 3 deceased women are listed in table 3 and illustrated in the Kaplan-Meier plot shown in figure 2. The 3 patients
Table 3. Characteristics of deceased women $(\mathrm{n}=3)$

\begin{tabular}{ll}
\hline pT stage & \\
pT1 & 2 \\
pT2 & 1 \\
pN stage & 3 \\
$\quad$ Positive & \\
Grade of invasive carcinoma & 2 \\
$\quad$ G2 & 1 \\
G3 & \\
Successful excision & 2 \\
$\quad$ Successful first excision & 1 \\
2 reexcisions & \\
Type of surgery & 2 \\
$\quad$ Breast-conserving therapy & 1 \\
Mastectomy & \\
IHC status & 2 \\
$\quad R^{+}$ & 1 \\
PR & \\
Her2/neu & \\
Triple & \\
Descriptors of calcification morphology & \\
Fine pleomorphic & 3
\end{tabular}

with breast cancer-specific death showed fine pleomorphic calcifications at the time of diagnosis. All 3 women showed nodal-positive invasive carcinoma at the time of diagnosis, none of these were of low grade.

\section{Discussion}

There are conflicting results in the literature regarding the prognostic value of fine linear or fine linear branching calcifications for survival. Several authors found an increased rate of deaths $[1,6,12$, $13,19]$ with rate between 10 and $50 \%$, others did not [10, 20]. In our cohort only 15 of 99 lesions contained fine linear or fine-linear branching calcifications. These showed a higher rate of grade 3 DCIS and HER2/neu positivity, yet without increased nodal positivity. James et al. [10] found that the presence of fine linear or fine-linear branching calcifications was not an independent prognostic factor, but was closely related to histological grade. In our study the overall survival rate was high (93.6\%). All 3 deceased cases showed fine pleomorphic microcalcifications on preoperative mammograms.

Several authors have reported that mammographic calcifications are a prognostic indicator for residual disease at excision [14, 21-23]. Clear surgical margins greater than $1 \mathrm{~mm}$ were found by Kurniawan et al. [24] in $79.3 \%$ of pure invasive cases, but in only $69.9 \%$ of invasive cancer with DCIS, and $53.5 \%$ of women with DCIS. Thomas et al. [25] reported a successful first surgery rate of $1,981 / 2,564(77.3 \%)$ cases with successful primary breast-conserving therapy in $1,430 / 2,564(55.8 \%)$ and primary mastectomy in $551 / 2,564(21.9 \%)$ cases. Their final breast-conserving rate was $1,810 / 2,564(70.6 \%)$. The successful first surgery rate of our cohort was $76.8 \%$ (76 out of 99 cases). Breast conservation was achieved in $73.7 \%$ (73 of 99 cases). Evans et al. [11] found a successful first ex- 
cision rate for pleomorphic and fine linear or fine-linear branching type descriptors superior to that for round/punctate microcalcifications. In our study the successful first excision rate of round/ punctate microcalcifications was low (62.5\%; 5 of 8 cases).

Kini et al. [26] found that the presence of microcalcifications on preoperative mammography were associated with a significantly increased risk of local recurrence ( $22 \%$ vs. $6 \%)$. In a recent study, Holmberg et al. [7] showed an increased risk of local recurrence for fine linear or fine linear branching microcalcifications. Our longterm observation showed a limited number of recurrences (10.6\%) for all descriptors of calcification morphology, except for coarse heterogeneous with no recurrence. Local recurrence occurred throughout the follow-up period and more than 5 years after initial surgery. However, recurrences did not negatively impact survival or freedom of metastasis. The necessity and duration of mammographic follow-up is still a matter of debate [27].

It has been postulated that triple-negative breast cancers constitute $10-17 \%$ of all breast cancers [28]. Billar et al. [29] found that triple-negative breast cancers comprised $11.6 \%$ of the invasive breast cancers in their single institution database. On mammography, triple negative breast cancers usually presented with a mass or with focal asymmetry, and were less associated with calcifications [30]. The triple negative rate of our cohort with microcalcificationassociated DCIS and invasive breast cancers was only $6.1 \%$. According to the literature [31-35], in $15-25 \%$ of breast carcinomas, there is amplification of the HER2/neu gene, an excess of the HER2 protein in the cancer cells and a high risk of recurrence. Ko et al. [30] found that, in contrast to triple negativity, HER2/neu positivity was more likely to be associated with calcifications. Microcalcifications are generally associated with HER $2 /$ neu positivity $[8,36$, 37]. Evans et al. [38] demonstrated significant differences in the mammographic feature of HER2/neu-positive and -negative disease. HER2/neu-positive DCIS more commonly showed calcification, ductal distribution, and rod-shaped and granular type calcifi- cation. In our study based on non-palpable microcalcification-associated specimens, the HER2/neu-positivity rate was $29.3 \%$. Compared to HER2/neu-negative disease, HER2/neu-positive disease was more often associated with positive axillary lymph node status, grade 3 DCIS, unsuccessful first surgery, and a higher rate of recurrence.

Inter- and intra-observer variability apply to mammographic descriptors, histological grading as well as immunohistochemistry. Use of different grading systems and techniques is a further source for inter-study variability. We did not evaluate the extent of calcifications and tumor extent by histopathology. Evans et al. [11] found that the mammographic bi-dimensional extent is a powerful predictor of successful single therapeutic wide local excision of DCIS when combined with histological grade and/or calcification morphology. Although in our study great care and effort was applied to achieve comprehensive follow-up, the follow-up was not complete for all women. The number of patients who died from their disease, or had recurrences, was small in this single center study, thus statistical significance was limited. Future data from large register studies will be of interest.

In this long-term follow-up study, microcalcification-associated, non-palpable breast cancers were treated with a high rate of breast-conserving therapy. The mortality rate was low and related to node-positive status at the time of diagnosis. Recurrences were found throughout the follow-up period. Therefore, mammography should be considered early and follow-up should be longer than 5 years.

\section{Disclosure Statement}

There was no sponsorship or funding arrangements for this research and no conflict of interest for any author.

\section{References}

1 Tabár L, Chen H, Duffy S, et al.: A novel method for prediction of long-term outcome of women with tla, $\mathrm{tl}$, and 10-14 mm invasive breast cancers: A prospective study. Lancet 2000;355:429-433.

2 Thurfjell E, Thurfjell MG, Lindgren A: Mammographic finding as predictor of survival in $1-9 \mathrm{~mm}$ invasive breast cancers. Worse prognosis for cases presenting as calcifications alone. Breast Cancer Res Treat 2001;67:177-180.

3 Gajdos C, Tartter PI, Bleiweiss IJ, et al.: Mammographic appearance of nonpalpable breast cancer reflects pathologic characteristics. Ann Surg 2002;235: 246-251.

4 Evans AJ, Pinder SE, Snead DR, et al.: The detection of ductal carcinoma in situ at mammographic screening enables the diagnosis of small, grade 3 invasive tumours. Br J Cancer 1997;75:542-544.

5 Zunzunegui RG, Chung MA, Oruwari J, et al.: Castingtype calcifications with invasion and high-grade ductal carcinoma in situ: A more aggressive disease? Arch Surg 2003;138:537-540.
Bennett RL, Evans AJ, Kutt E, et al.: Pathological and mammographic prognostic factors for screen detected cancers in a multi-centre randomised, controlled trial of mammographic screening in women from age 40 to 48 years. Breast 2011;20:525-528.

7 Holmberg L, Wong YN, Tabár L, et al.: Mammography casting-type calcification and risk of local recurrence in dcis: Analyses from a randomised study. Br J Cancer 2013;108:812-819.

8 Ling H, Liu ZB, Xu LH, et al.: Malignant calcification is an important unfavorable prognostic factor in primary invasive breast cancer. Asia Pac J Clin Oncol 2013;9: 139-145.

9 Silverstein M, Poller D, Waisman J, et al.: Prognostic classification of breast ductal carcinoma-in-situ. Lancet 1995;345:1154-1157.

10 James JJ, Evans AJ, Pinder SE, et al.: Is the presence of mammographic comedo calcification really a prognostic factor for small screen-detected invasive breast cancers? Clin Radiol 2003;58:54-62.
11 Evans A, Clements K, Maxwell A, et al.: Mammographic bi-dimensional product: A powerful predictor of successful excision of ductal carcinoma in situ. Clin Radiol 2007;62:787-791.

12 Tabar L, Tony Chen H, Amy Yen M, et al.: Mammographic tumor features can predict long-term outcomes reliably in women with 1-14-mm invasive breast carcinoma. Cancer 2004;101:1745-1759.

13 Pálka I, Ormándi K, Gaál S, et al.: Casting-type calcifications on the mammogram suggest a higher probability of early relapse and death among high-risk breast cancer patients. Acta Oncol 2007;46:1178-1183.

14 Holland R, Hendriks J, Vebeek A, et al.: Extent, distribution, and mammographic/histological correlations of breast ductal carcinoma in situ. Lancet 1990;335: 519-522.

15 Toi M, Benson JR, Winer EP, et al.: Preoperative systemic therapy in locoregional management of early breast cancer: Highlights from the kyoto breast cancer consensus conference. Breast Cancer Res Treat 2012; 136:919-926. 
16 American College of Radiology: Breast Imaging Reporting and Data System (BI-RADS), 4th ed. Reston, VA: American college of radiology, 2003.

17 D’Orsi CJ, Sickles EA, Mendelson EB, et al.: ACR BI-RADS ${ }^{\circledR}$ Atlas, Breast Imaging Reporting and Data System. Reston, VA, American College of Radiology, 2013.

18 Elston C, Ellis I: Pathological prognostic factors in breast cancer. I. The value of histological grade in breast cancer: Experience from a large study with long-term follow-up. Histopathology 1991;19:403-410.

19 Peacock C, Given-Wilson RM, Duffy SW: Mammographic casting-type calcification associated with small screen-detected invasive breast cancers: Is this a reliable prognostic indicator? Clin Radiol 2004;59:165-170.

20 Mansson E, Bergkvist L, Christenson G, et al.: Mammographic casting-type calcifications is not a prognostic factor in unifocal small invasive breast cancer: A populationbased retrospective cohort study. J Surg Oncol 2009;100:670-674.

21 Beron PJ, Horwitz EM, Martinez AA, et al.: Pathologic and mammographic findings predicting the adequacy of tumor excision before breast-conserving therapy. AJR Am J Roentgenol 1996;167:1409-1414.

22 MacMillan RD, Purushotham AD, Cordiner C, et al.: Predicting local recurrence by correlating pre-operative mammographic findings with pathological risk factors in patients with breast cancer. Br J Radiol 1995;68:445-449.

23 Koca B, Kuru B, Yuruker S, et al.: Factors affecting surgical margin positivity in invasive ductal breast cancer patients who underwent breast-conserving surgery after preoperative core biopsy diagnosis. J Korean Surg Soc 2013;84:154-159.

24 Kurniawan ED, Wong MH, Windle I, et al.: Predictors of surgical margin status in breast-conserving surgery within a breast screening program. Ann Surg Oncol 2008 15:2542-2549.

25 Thomas J, Evans A, Macartney J, et al.: Radiological and pathological size estimations of pure ductal carcinoma in situ of the breast, specimen handling and the influence on the success of breast conservation surgery: A review of 2564 cases from the sloane project. Br J Cancer 2010;102:285-293.

26 Kini VR, Vicini FA, Frazier R, et al.: Mammographic, pathologic, and treatmentrelated factors associated with local recurrence in patients with early-stage breast cancer treated with breast conserving therapy. Int J Radiat Oncol Biol Phys 1999;43: 341-346.

27 Maxwell AJ, Evans AJ, Carpenter R, et al.: Follow-up for screen-detected ductal carci noma in situ: Results of a survey of uk centres participating in the sloane project. Eur J Surg Oncol 2009;35:1055-1059.

28 Foulkes WD, Smith IE, Reis-Filho JS: Triple-negative breast cancer. N Engl J Med 2010;363:1938-1948.

29 Billar JA, Dueck AC, Stucky CC, et al.: Triple-negative breast cancers: Unique clinical presentations and outcomes. Ann Surg Oncol 2010;17 Suppl 3:384-390.

30 Ko ES, Lee BH, Kim HA, et al.: Triple-negative breast cancer: Correlation between imaging and pathological findings. Eur Radiol 2010;20:1111-1117.

31 Joensuu H, Kellokumpu-Lehtinen PL, Bono P, et al.: Adjuvant docetaxel or vinorelbine with or without trastuzumab for breast cancer. N Engl J Med 2006;354:809-820.

32 Slamon DJ, Godolphin W, Jones LA, et al.: Studies of the HER-2/neu proto-oncogene in human breast and ovarian cancer. Science 1989;244:707-712.

33 Press MF, Bernstein L, Thomas PA, et al.: HER-2/neu gene amplification characterized by fluorescence in situ hybridization: Poor prognosis in node-negative breast carcinomas. J Clin Oncol 1997; 15:2894-2904.

34 Ravdin PM, Chamness GC: The c-erbB-2 proto-oncogene as a prognostic and predictive marker in breast cancer: A paradigm for the development of other macromolecular markers-a review. Gene 1995; 159:19-27.

35 Owens MA, Horten BC, Da Silva MM: HER2 amplification ratios by fluorescence in situ hybridization and correlation with immunohistochemistry in a cohort of 6556 breast cancer tissues. Clin Breast Cancer 2004;5:63-69.

36 Sun SS, Zhang B, Zhao HM, Cao XC: Association between mammographic features and clinicopathological characteristics in invasive ductal carcinoma of breast cancer. Mol Clin Oncol 2014;2:623-629.

37 Li JJ, Chen C, Gu Y, et al.: The role of mammographic calcification in the neoadjuvant therapy of breast cancer imaging evaluation. PLoS One 2014;9:e88853.

38 Evans AJ, Pinder SE, Ellis IO, et al.: Correlations between the mammographic features of ductal carcinoma in situ (DCIS) and c-erbB-2 oncogene expression. Nottingham breast team. Clin Radiol 1994;49:559-562. 